\title{
Educação a distância: configurações, políticas e contradições engendradas no trabalho docente'
}

\author{
Elcio Gustavo Benini \\ Maria Dilnéia Espíndola Fernandes ${ }^{3}$ \\ Carla B. Zandavalli M. Araujo 4
}

\section{Resumo}

O trabalho objetiva desvelar as contradições que se apresentam na organização do trabalho docente na modalidade a distância. A construção do campo de análise incluiu a sistematização dos dados educacionais fornecidos pelo "Instituto Nacional de Estudos e Pesquisas Educacionais Anísio Teixeira (Inep)", os documentos que norteiam a política educacional e a investigação empírica de Instituições de Ensino Superior. Constatamos que as Tecnologias da Informação e Comunicação (TICs) constituem a base objetiva dos discursos e das práticas sobre a democratização do acesso ao ensino superior. De fato, observamos que, na primeira década do século $\mathrm{XXI}$, houve um crescimento vultoso de matrículas no ensino superior brasileiro na modalidade a distância. Tal crescimento, contudo, tem engendrado contradições, como a intensificação, a alienação, a precarização e a divisão do trabalho docente.

Palavras-chave: Política educacional. Educação a distância. Trabalho docente.

\section{Introdução}

No decorrer dos últimos anos, principalmente a partir da primeira década dos anos 2000, a educaçáo a distância, devido ao crescimento exponencial

1 O estudo contou com financiamento da Fundação de Apoio ao Desenvolvimento do Ensino. Ciência e Tecnologia no Estado de Mato Grosso do Sul (FUNDECT), por meio do edital Universal no 14/2009.

2 Professor adjunto do Centro de Ciências Humanas e Sociais da Universidade Federal de Mato Grosso do Sul. E-mail:elciobenini@yahoo.com.br.

3 Doutora em Educação pela Universidade Estadual de Campinas (UNICAMP). Professora Associada 3 no Programa de Pós-Graduação em Educação da Universidade Federal de Mato Grosso do Sul.

E-mail:mdilneia@uol.com.br.

4 Doutora em Educação pela Universidade Federal de Mato Grosso do Sul e Professora Adjunta do Centro de Ciências Humanas e Sociais desta Universidade. E-mail: carlabzandavalli@gmail.com. 
de cursos e matrículas, tem-se apresentado como uma dimensão crescente no ambiente acadêmico, não apenas na oferta de cursos, mas também como objeto de investigação científica. Por agregar mais recursos tecnológicos nos processos de ensino e aprendizagem que a modalidade presencial, assim como por proporcionar novas formas de comunicaçáo, tal modalidade parece justificar a sua emersão pela possibilidade cada vez mais concreta da superação de duas variáveis paradigmáticas do ambiente escolar: o tempo e o espaço.

A educaçáo a distância, de acordo com Peters (2006, 2009), tem a sua singularidade na aplicação racional da organização do trabalho. Por somar as tecnologias de informação e comunicação existentes com a organização racional do trabalho, Peters a define como a forma mais industrializada de ensino e aprendizagem. Para esse apologeta da educação a distância, tal modalidade de ensino representa não somente a revoluçáo na organização do trabalho docente e nos métodos de ensino e aprendizagem, mas a viabilidade efetiva de barateamento e democratizaçáo do acesso ao ensino superior.

A tese da democratização, de fato, é amplamente disseminada, seja em âmbito acadêmico (DELORS, 1996; BELLONI, 2009; LITTO; FORMIGA, 2009), seja na sua inserção nos processos de constituição das políticas educacionais (BRASIL, 2001a, 2003). A relação, portanto, entre produtividade e democratização constitui um dos elos determinantes nas descontinuidades que se encontram no cerne do processo do trabalho docente nessa modalidade. Este trabalho busca desvelar as principais contradiçóes do crescimento produtivo dessa modalidade de ensino superior, expressas principalmente no aumento vultoso das matrículas e na descontinuidade da relaçáo educativa entre professor e aluno. Para tal, elege-se, principalmente, a organização e a divisão do trabalho docente e os programas de política educacional em curso inseridos no processo.

A construção do campo de investigação e análise ocorreu por meio da sistematização de dados educacionais do Instituto Nacional de Estudos e Pesquisas Educacionais Anísio Teixeira (Inep), do estudo das políticas educacionais em curso e de pesquisa em Instituiçóes de Ensino Superior. Sobre este último campo de investigação, que permitiu uma visão dialética entre os aspectos universais do processo de trabalho lato sensu e as singularidades e 
particularidades do processo de trabalho docente da educação a distância, foram realizadas entrevistas e aplicados questionários em Instituiçóes de Ensino Superior (IES), denominadas Universidade Federal Alfa e Universidade Privada Beta.

Seguindo a proposta metodológica de caminhar do concreto para o abstrato e retomá-lo a partir da relação entre o lógico e o histórico (MARX, 2003), a exposiçáo inicia-se com um panorama da educação a distância no ensino superior, a partir da análise das matrículas e das suas relaçóes com a modalidade presencial e entre os setores público e privado. Por meio dos dados do Inep, analisamos o curso de Pedagogia, pela ênfase dada pelas políticas de formação de professores, além do seu número expressivo de matrículas na modalidade a distância. Dando sequência, apontamos as principais diretrizes da política educacional nessa modalidade, focalizando principalmente aspectos relativos ao processo e às determinaçóes do trabalho docente. Por fim, mostramos algumas particularidades observadas nas duas instituiçóes pesquisadas, a fim de demonstrar a concreticidade das contradiçóes decorrentes do aparato produtivo no cerne do trabalho docente.

\section{Os números da educação a distância}

Para Noble (2000, 2002), na atualidade o boom da educação a distância - cujo discurso da democratizaçáa e da autonomia é amplificado pelas novas possibilidades oriundas das redes virtuais, proporcionadas pela revoluçáo informacional na área da telemática - pode ser entendido como uma nova corrida do ouro, cuja principal distinção em relação às suas formas históricas antecedentes é, "[...] acima de tudo, de colher os lucros da especulação financeira na indústria da educação, através das stock-options e entradas na Bolsa” (NOBLE, 2000, [s. p.]).

No cenário brasileiro, entre os anos 2000 e 2012, a educação a distância teve um crescimento considerável, seja na quantidade de matrículas, seja no número de instituiçóes credenciadas. $\mathrm{O}$ Gráfico 1 exibe o número de instituiçóes e matrículas que saltaram, respectivamente, de 7 para 150, e de 1.682 para 1.113 .850 , no período. 


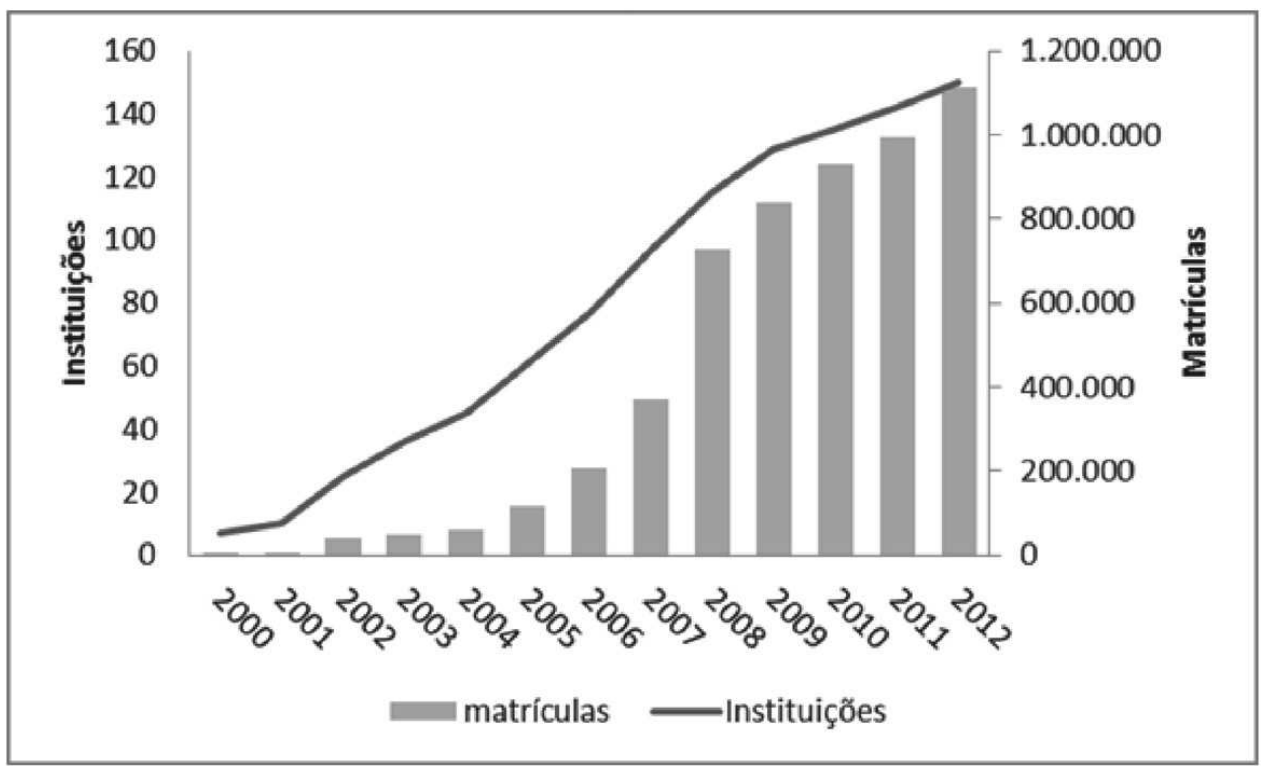

Gráfico I - Número de instituições e matrículas no ensino superior na modalidade a distância Brasil (2000-20I2)

Fonte: Elaborado pelos autores a partir das Sinopses Estatísticas da Educação Superior (Inep, 2012).

Chamam a atenção nesses números, além do crescimento acelerado, a densidade e a concentração por instituição. Quando comparadas com a modalidade presencial e verificadas a partir das dimensóes público e privado, ficam ainda mais evidentes, conforme demonstram os Gráficos 2 e 3.

De acordo com o Gráfico 2, enquanto na modalidade presencial a relaçáo entre o número de matrículas por instituição permaneceu estável - 2.283 no ano de 2000 e 2.452 no ano de 2012 -, na modalidade a distância tal relaçáo apontou uma concentração crescente, passando de 240 matrículas em 2000 para 7.426 em 2012, o que a priori demonstra que a modalidade a distância tende a ser mais procurada que a modalidade presencial. 


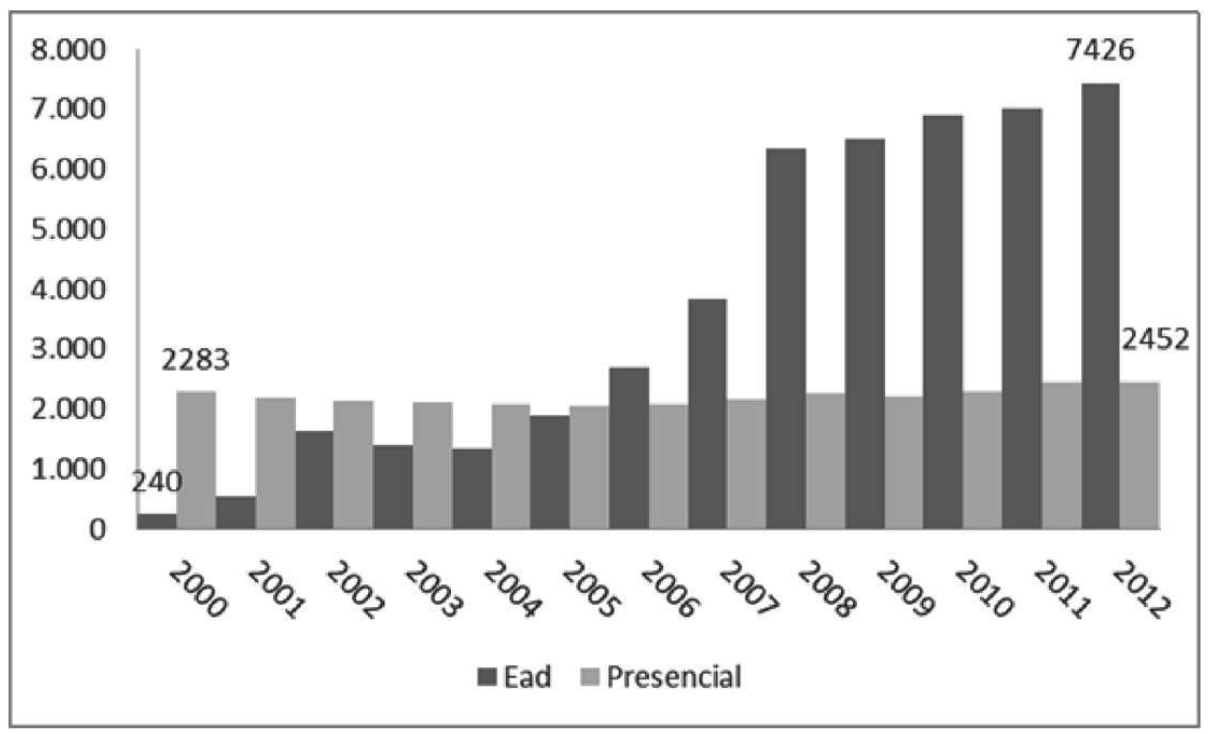

Gráfico 2 - Total de matrículas por instituições no ensino superior nas modalidades presencial e a distância no Brasil (2000-20I2)

Fonte: Elaborado pelos autores a partir das Sinopses Estatísticas da Educação Superior (INEP, 20/2).

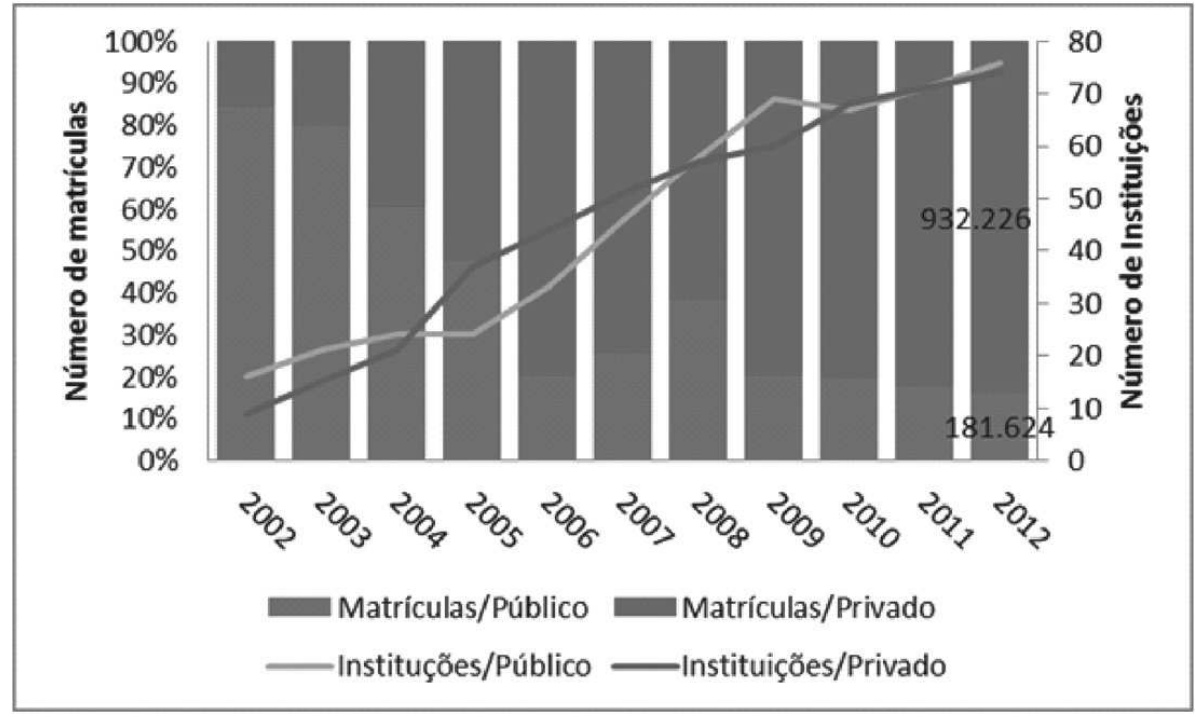

Gráfico 3 - Número de matrículas (\%) e de Instituições no ensino superior na modalidade a distância no Brasil (2002-20I2)

Fonte: Elaborado pelos autores a partir das Sinopses Estatísticas da Educação Superior (Inep, 2012).

Mas é na relação entre as dimensões pública e privada que a tendência à concentração do atual estágio monopolista do capitalismo (MÉSZÁROS, 
2002) é mais pujante. De acordo com o Gráfico 3, o ensino superior na modalidade a distância configurou-se no final da série histórica, em 2012, com 932.226 matrículas $(83,6 \%)$ e 74 instituiçóes no setor privado; no setor público, com 181.624 matrículas $(16,4 \%)$ e 76 instituiçóes. Portanto, enquanto no setor público a relação entre matrículas e instituiçóes é de 2.454 , no setor privado tal relação é de 12.597 matrículas por instituição. Utilizando apenas esse indicador, vemos que as Instituiçóes do setor privado, além de concentrarem mais matrículas, são cerca de cinco vezes mais demandadas.

Quando analisamos apenas o setor privado, a concentraçáo torna-se mais evidente e demonstra que esse setor de mercado promove a oligopolização. Conforme os dados demonstrados no Gráfico 4, apenas as cinco Instituiçóes com o maior número de matrículas, juntas, somam 550.095 matrículas, o que representa $58,7 \%$ do montante no setor privado e $49,3 \%$ do total de matrículas na modalidade a distância.

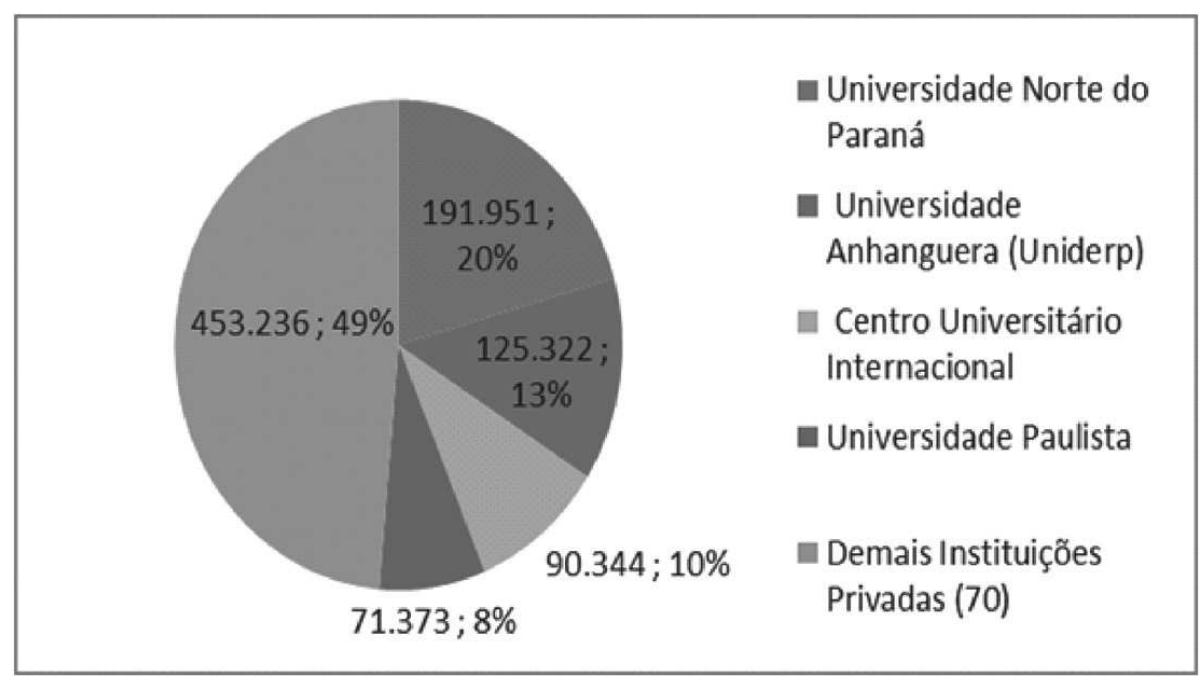

\section{Gráfico 4 - Matrículas (\%) no ensino superior na modalidade a distância no setor privado, por instituição no Brasil (20I2)}

Fonte: Elaborado pelos autores a partir das Sinopses Estatísticas da Educação Superior (Inep, 20/2).

De acordo com o trabalho de Daniel (1999), que demonstra a concentração e a oligopolização do setor em nível internacional, o sucesso - lucrativo dessas megauniversidades baseia-se na divisão sistemática do trabalho, o que, em última análise, significa a aplicação do princípio taylorista da organização racional e instrumental do trabalho e a divisão entre planejamento e execuçáo. 
A key strength of correspondence study is its flexibility for both student and institution. The course materials are portable and, because the student relates to the institution as an individual, communicating by mail and/or telephone, there are few constraints of time and place. For the institution the systems is flexible in two related ways. It permits a division of labour (e.g., course authors and course tutors can be different people) and it can be expanded rapidly with economies scale. Economies of scale give correspondence education another strength: operating with large numbers of students provides the resources needed to produce high quality learning materials. This is a key competitive advantage of the mega-universities ${ }^{5}$. (DANIEL, 1999, p. 57).

Analisando o curso de Pedagogia, a configuração entre as modalidades e os setores, conforme o Gráfico 5, demonstra que a modalidade a distância nas universidades privadas somou, no ano de 2012, 258.579 matrículas, o que corresponde a $43 \%$ do total de matriculados no curso, sendo assim a maior concentração de matrículas, considerando-se as duas modalidades e os setores público e privado.

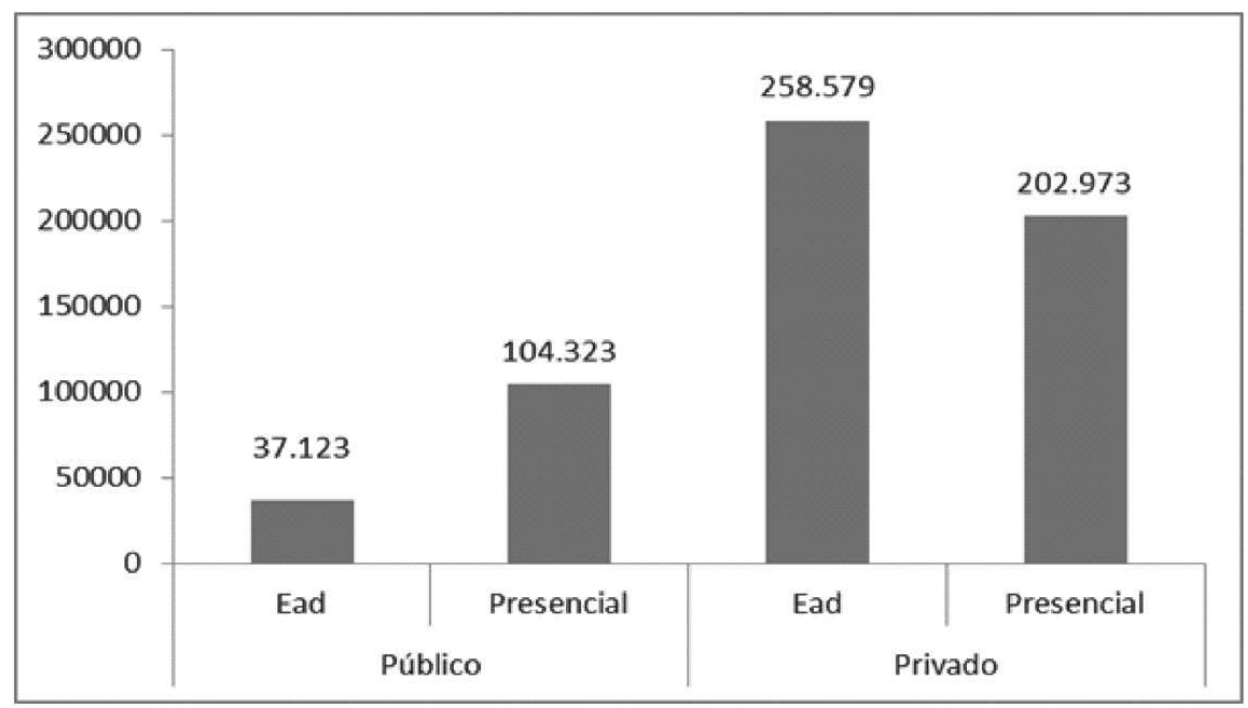

\section{Gráfico 5 - Matrículas no curso de Pedagogia, nas modalidades presencial e a distância, nos setores público e privado no Brasil (20I2)}

Fonte: Elaborado pelos autores a partir das Sinopses Estatísticas da Educação Superior (Inep, 20 I2).

5 Um dos pontos fortes do ensino por correspondência é a sua flexibilidade, tanto para o aluno como para a instituição promotora. Os materiais do curso são portáteis e, pelo fato de o aluno se relacionar com a instituição como um individuo, comunicando-se por e-mail elou telefone, há poucas restrições de tempo e lugar. Para a instituição, o sistema é flexivel de duas maneiras relacionadas. Ele permite uma divisão de trabalho (por exemplo, os autores e os tutores do curso podem ser pessoas diferentes) e pode ser expandido rapidamente com economias de escala. Economias de escala dão ao ensino por correspondência outro ponto forte: operar com um grande número de estudantes fornece os recursos necessários para a produção de materiais de aprendizagem de alta qualidade. Esta é uma das principais vantagens competitivas das megauniversidades (Tradução nossa). 


\section{Política educacional e educação a distância}

Embora a história da educação a distância no Brasil esteja próxima de completar um século, de acordo com o comentário de Giolo (2008), sob o ângulo da oferta regular de cursos de graduação, sua história é relativamente recente; iniciou-se nos anos 1990.

Foi com a Lei no 9.394, Lei das Diretrizes e Bases da Educação (LDB), em 1996, que o marco institucional nacional da modalidade de ensino se estabeleceu (BRASIL, 1996b). Embora tal marco apenas tivesse apontado as diretrizes gerais para tal modalidade de ensino, sendo necessárias novas normatizaçôes para a efetivação/regulamentação do setor, foi a LDB que 'abriu as portas' para a sua entrada no sistema regular educacional. Para Giolo (2008, p. 2), a LDB concedeu "[...] estatuto de maioridade para a educaçáo a distância [...]", garantindo “[...] incentivo do poder público, espaço amplo de atuaçáo (todos os níveis e modalidades) e tratamento privilegiado no que se refere à utilização de canais de radiodifusão". Não obstante a LDB faça outras referências à educaçáo a distância em seu texto, é o artigo 80 que aborda especificamente a modalidade. De acordo com o texto:

Art. 80 O Poder Público incentivará o desenvolvimento e a veiculação de programas de ensino a distância, em todos os níveis e modalidades de ensino, e de educação continuada. $\S 1^{\circ} A$ educação a distância, organizada com abertura e regime especiais, será oferecida por instituições especificamente credenciadas pela União.

$\S 2^{\circ}$ A União regulamentará os requisitos para a realização de exames e registro de diploma relativos a cursos de educação a distância.

$\S 3^{\circ}$ As normas para produção, controle e avaliação de programas de educação a distância e a autorização para sua implementação caberão aos respectivos sistemas de ensino, podendo haver cooperação e integração entre os diferentes sistemas.

$\S 4^{\circ} \mathrm{A}$ educação a distância gozará de tratamento diferenciado, que incluirá:

I - custos de transmissão reduzidos em canais comerciais de radiodifusão sonora e de sons e imagens;

II - concessão de canais com finalidades exclusivamente educativas;

III - reserva de tempo mínimo, sem ônus para o Poder Público, pelos concessionários de canais comerciais. (BRASIL, 1996, [s. p.]).

A segunda referência a respeito da educação a distância no texto da LDB encontra-se no artigo 65, que versa sobre a formaçáo docente. De acordo com os parágrafos segundo e terceiro: 
$\S 2^{\circ} \mathrm{A}$ formação continuada e a capacitação dos profissionais de magistério poderão utilizar recursos e tecnologias de educação a distância.

$\S 3^{\circ} \mathrm{A}$ formação inicial de profissionais de magistério dará preferência ao ensino presencial, subsidiariamente fazendo uso de recursos e tecnologias de educação a distância. (BRASIL, 1996, [s. p.]).

Embora o segundo parágrafo enfatize a autorização do uso da educação a distância na formação dos docentes, é a indicação da preferência do ensino presencial, no terceiro parágrafo, que chama a atençáo. Conforme os dados do Gráfico 5, a maior parcela de matrículas no curso de Pedagogia configura-se na modalidade a distância no setor privado; no total, em 2012, a modalidade presencial, considerando-se os dois setores, foi de 307.296 (50,9\%), ou seja, praticamente a metade. Assim, aquilo que era 'subsidiariamente' tratado pela LDB tornou-se, cerca de 18 anos depois, de importância substantiva na configuração da formação dos pedagogos.

Com o intuito de regulamentar o artigo 80 da LDB, dois anos depois se seguiu o Decreto no 2.494/1998 (BRASIL, 1998a). Constituído de 13 artigos, o decreto teve a tarefa de regulamentar uma modalidade de ensino sem a contrapartida de uma discussão ampla e nacional sobre o assunto, seja em termos acadêmicos, seja em termos políticos. Com efeito, constituiu-se no principal instrumento normativo para a modalidade, sendo somente revisado e aprofundado em algumas questôes.

O primeiro artigo do decreto, como não poderia deixar de ser, trouxe a definição da educação a distância, uma vez que a LDB não versou diretamente sobre o tema.

Art. $1^{\circ}$ Educação a distância é uma forma de ensino que possibilita a autoaprendizagem, com a mediação de recursos didáticos sistematicamente organizados, apresentados em diferentes suportes de informação, utilizados isoladamente ou combinados, e veiculados pelos diversos meios de comunicação.

Parágrafo Único - Os cursos ministrados sob a forma de educação a distância serão organizados em regime especial, com flexibilidade de requisitos para admissão, horários e duração, sem prejuízo, quando for o caso, dos objetivos e das diretrizes curriculares fixadas nacionalmente. (BRASIL, 1998a, [s. p.]).

Como se observa, o mencionado decreto enfatiza, na definição da educação a distância, a questão da autoaprendizagem. Mais importante que isso, 
entretanto, é o entendimento de mediação instituído por meio do Decreto no 2.494/1998 (BRASIL, 1998a). Em dissonância com as discussões acadêmicas (MILL, 2002; PETERS, 2006, 2009; NEDER, 2009; LANCILLOTTI, 2008; BENINI, 2012), a categoria mediação não aparece no documento como uma relação social, e sim em referência aos recursos didáticos e instrumentos de trabalho. Ou seja, para o Decreto no 2.494/1998, a tecnologia e os instrumentos de trabalho sáo os mediadores do conhecimento, enfim, entre a autoaprendizagem do aluno e o conteúdo, e não o professor.

Outro item de suma relevância no decreto em questão é que, em nenhum momento do texto, a existência do tutor é normatizada. Vale ressaltar que o tutor, para grande parte dos estudiosos do tema (MOORE; KEARSLEY, 2007; BELLONI, 2009; NEDER, 2009), é visto como o principal ator no processo de educação a distância.

Na sequência, foi publicado o Decreto no 2.561/1998 (BRASIL, 1998b). Esse decreto, de dois artigos, teve como objetivo alterar os artigos 11 e 12 do decreto anterior. Trata das competências dos sistemas estaduais e municipais de ensino, ampliando-as para a oferta da educação a distância também em cursos técnicos e profissionalizantes, uma vez que no decreto anterior o texto delegava competências apenas sobre o ensino fundamental de educação de jovens e adultos e do ensino médio.

Embora os decretos de 1998 sobre a educação a distância tenham regulamentado a modalidade durante sete anos, sendo revogados a partir de 2005 e, a partir daí, uma série de normatizaçóes em níveis inferiores tenham sido promovidas, nesse ínterim, alguns documentos tidos como referenciais de qualidade foram elaborados pela Secretaria de Educação a Distância (SEED), do Ministério da Educaçáo (MEC). O primeiro foi intitulado de "Indicadores de Qualidade para Cursos de Graduação a Distância", publicado em 2000. O segundo, "Referenciais de Qualidade para Cursos a Distância", foi publicado em 2003. O último, "Referenciais de Qualidade para Educação Superior a Distância”, foi publicado em 2007 (BRASIL, 2000, 2003, 2007b).

O primeiro referencial, já no início do texto, demonstra a sua importância, ao enfatizar que, embora os indicadores sugeridos náo tivessem força de lei, "[...] servirão para orientar as Instituiçóes e as Comissóes de Especialistas que forem analisar projetos de cursos de graduaçáo a distância” (BRASIL, 
2000, [s. p.]). Também o texto expressa o entendimento e a justificativa para o desenvolvimento do setor, uma vez que é "[...] um meio de democratizar o acesso ao conhecimento e de expandir oportunidades de aprendizagem ao longo da vida" (BRASIL, 2000, [s. p.]), em consonância com o discurso disseminado. É na caracterizaçáo dessa modalidade de ensino, contudo, que o texto introduz uma inovação primordial em relação aos decretos até então instituídos. Diante disso:

[...] considera-se que a diferença básica entre educação presencial e a distância está no fato de que, nesta, o aluno tem acesso ao conhecimento e desenvolve hábitos, habilidades e atitudes relativos ao estudo, à profissão e à sua própria vida, no tempo e local que the são adequados, não com a ajuda em tempo integral da aula de um professor, mas com a mediação de professores (orientadores ou tutores), atuando ora a distância, ora em presença e com o apoio de materiais didáticos sistematicamente organizados, apresentados em diferentes suportes de informação, utilizados isoladamente ou combinados, e veiculados através dos diversos meios de comunicação. (BRASIL, 2000, [s. p.]).

Pela primeira vez, entrou em cena a figura do tutor na modalidade, em um documento que, embora sem efeito de lei, serviu como principal regulação. Vale ressaltar a percepção do texto sobre tal ator, como um mediador, expressando-se, assim, uma relação social educativa substancial para se compreender a organização do processo de trabalho docente na educaçáo a distância.

De acordo com o segundo referencial, de 2003, intitulado "Referenciais de Qualidade para Cursos a Distância", a raison d'être da educaçáo a distância é a democratização. Assim, conforme o referencial, tal modalidade de ensino é "[...] um meio de democratizar o acesso ao conhecimento e de expandir oportunidades de trabalho e aprendizagem ao longo da vida" (BRASIL, 2003, [s. p.]).

Uma descontinuidade relevante do texto é a proposição de ser uma orientação mais ampla, não direcionada apenas à graduação a distância, mas também a demais modalidades e níveis de ensino. Assim, o texto objetiva expor sobre "[...] educação, sabendo que ela incorpora atividades de aprendizagem presenciais e atividades de aprendizagem a distância" (BRASIL, 2003, [s. p.]). Com efeito, a questão não é circunstancial, pois em 2001 o MEC, por meio da Portaria no 2.253/2001, ampliou as possibilidades da educação a 
distância e do uso das novas tecnologias de informação e comunicação, ao considerar e dispor sobre o artigo 81 da LDB que, de forma bem genérica, estabelece a permissão da "[...] organização de cursos ou instituiçóes de ensino experimentais" (BRASIL, 2001b, [s. p.]). Tendo em vista essa prerrogativa, a Portaria $\mathrm{n}^{\circ} 2.253 / 2001^{6}$ autoriza que todos os cursos presenciais utilizem $20 \%$ do total da carga horária a distância, desde que o Projeto Político-Pedagógico (PPP) do curso e o Plano de Ensino das disciplinas que usam tal metodologia de ensino sejam reformulados e aprovados por comissão especial do MEC (BRASIL, 2001b).

Um ponto preponderante do referencial de 2003 é a ênfase na comunicação. De acordo com o documento, "[...] um dos pilares para garantir a qualidade de um curso a distância é a comunicação entre professores e alunos" (BRASIL, 2003, [s. p.]). A comunicação entre os alunos também é enfatizada pelo texto, uma vez que, dadas as condiçóes das novas tecnologias, o isolamento típico das formas de educação a distância de primeira geração deveria ser superado. Essas duas questóes são primordiais, pois indicam uma contradição real.

De fato, como alerta Benini (2012), o desenvolvimento produtivista da educaçáo a distância tem-se estruturado de uma forma que tal comunicaçáo não é direta. Ainda que as novas tecnologias favoreçam uma maior interatividade, a mediação engendrada entre professor e aluno, ou seja, a figura da tutoria, como meio de conexão entre professor e aluno, torna tal processo de comunicação apenas uma potência, e não um ato.

No intervalo de tempo entre o referencial de 2003 e o último referencial de qualidade, intitulado "Referenciais de Qualidade para Educação Superior a Distância”, três importantes decretos (BRASIL, 2005, 2006, 2007a) foram promulgados. Eles são, atualmente, assim como o referencial de 2007, as principais normatizaçóes e orientaçóes para a modalidade.

Conforme o referencial de qualidade de 2007 estabelece, um ponto crucial do Decreto no 5.622/2005 (BRASIL, 2005, [s. p.]) é a nova caracterização da educação a distância. Assim, para os fins desse decreto,

6 Essa portaria, publicada no Diário Oficial da União em 19 de outubro de 2010, foi revogada pela Portaria $n^{\circ}$ 4.059, de 10 de dezembro de 2004. 
[...] caracteriza-se a educação a distância como modalidade educacional na qual a mediação didático-pedagógica nos processos de ensino e aprendizagem ocorre com a utilização de meios e tecnologias de informação e comunicação, com estudantes e professores desenvolvendo atividades educativas em lugares ou tempos diversos.

Um detalhe substancial nessa caracterização, que inclui uma mudança na compreensão da educação a distância em relação ao Decreto no 2.494/1998 (BRASIL, 1998a), diz respeito à concepção de tecnologia. Enquanto no primeiro decreto a educação a distância é caracterizada como "[...] uma forma de ensino que possibilita a autoaprendizagem, com a mediaçáo de recursos didáticos sistematicamente organizados, apresentados em diferentes suportes de informação" (BRASIL, 1998, [s. p.]), e assim a tecnologia é considerada a mediação, no Decreto no 5.622/2005 (BRASIL, 2005), a tecnologia é vista como um instrumento de auxílio na mediação, e não como a mediação per se. Essa questáo é de suma relevância, pois o entendimento da mediação como um "objeto", e não como uma "relaçáo social", esconde como ela é organizada e sistematizada. Assim, o Decreto no 5.622/2005 (BRASIL, 2005) exibe uma descontinuidade qualitativa significativa em relação ao Decreto no 2.494/1998 (BRASIL, 1998a).

Ainda que o Decreto no 5.622/2005 tenha sido complementado pelo Decreto $n^{\circ} 5.773 / 2006$ e pelo Decreto no 6.303/2007 (BRASIL, 2005, 2006, 2007a), no que diz respeito à tutoria, o Decreto no 5.622/2005 (BRASIL, 2005) - o primeiro texto com poder de lei a fazer referência à tutoria - apenas introduz a questáo de forma sucinta, informando que é responsabilidade das instituições a "[...] seleção e capacitação dos professores tutores" (BRASIL, 2005, [s. p.]). Portanto, é apenas no documento "Referenciais de Qualidade para Educação Superior a Distância" (BRASIL, 2007b) que a questáo da tutoria realmente é evidenciada ${ }^{7}$.

No texto de 2007, há um indicador de qualidade que se refere justamente à "Equipe Multidisciplinar", no qual se vê com detalhes o papel de cada ator. No indicador anterior "Avaliaçáa", que trata tanto do processo de avaliação da aprendizagem quanto da avaliação institucional, é interessante notar como o vínculo do professor e tutor é definido. Ao abordar o "Corpo Docente, Corpo de Tutores, Corpo Técnico-Administrativo e Discentes”, o texto relaciona como indicador de qualidade das instituiçóes:

7 Nesse texto, o radical "tutor" aparece 60 vezes. 
a) Corpo docente, vinculado à própria instituição, com formação e experiência na área de ensino e em educação a distância;

b) Corpo de tutores com qualificação adequada ao projeto do curso;

c) Corpo de técnico-administrativos integrado ao curso e que presta suporte adequado, tanto na sede como nos polos;

d) Apoio à participação dos estudantes nas atividades pertinentes ao curso, bem como em eventos externos e internos. (BRASIL, 2007b, p. 18).

De acordo com o texto, além da clara divisão entre docente e tutor, constatamos que, enquanto o corpo docente "vinculado à própria instituição" é um indicador de qualidade, o silêncio sobre isso quanto ao grupo de tutores leva a crer que o tipo de relacionamento entre tutor e instituição não é um indicador de qualidade. Essa questão demonstra que a relação entre tutor e instituição é um dos grandes problemas da educaçáo a distância, principalmente no setor público, que vem resolvendo tal problemática com o uso de bolsas que não implicam vínculo empregatício e que, portanto, excluem os direitos trabalhistas decorrentes do vínculo. Mas é no indicador "Equipe Multidisciplinar" dos referenciais de 2007 que o processo de trabalho docente é citado de forma mais clara. Uma questão preliminar, expressa nesse indicador, é a dificuldade de se detectar um padrão para a estrutura do processo de trabalho docente, uma vez que "[...] há uma diversidade de modelos, que resulta em possibilidades diferenciadas de composiçáo dos recursos humanos necessários à estruturação e ao funcionamento de cursos nessa modalidade" (BRASIL, 2007b, p. 19).

Mesmo reconhecendo tal dificuldade, os referenciais de 2007 incluem uma estrutura mínima a respeito da equipe multidisciplinar, que deve ser composta de: docentes, tutores e pessoal técnico-administrativo. O docente, de acordo com os referenciais de 2007, deve:

a) estabelecer os fundamentos teóricos do projeto;

b) selecionar e preparar todo o conteúdo curricular articulado a procedimentos e atividades pedagógicas;

c) identificar os objetivos referentes a competências cognitivas, habilidades e atitudes;

d) definir bibliografia, videografia, iconografia, audiografia, tanto básicas quanto complementares;

e) elaborar o material didático para programas a distância;

f) realizar a gestão acadêmica do processo de ensino-aprendizagem, em particular motivar, orientar, acompanhar e avaliar os estudantes;

g) avaliar-se continuamente como profissional participante do coletivo de um projeto de ensino superior a distância. (BRASIL, 2007b, p. 20). 
Ainda que nas entrelinhas ou indiretamente se perceba que uma das atividades do docente é ministrar aulas, o trecho supracitado é muito mais enfático em atribuir atividades de planejamento do que de execução ao docente, uma vez que ele deve "[...] realizar a gestáo acadêmica do processo de ensino-aprendizagem, em particular motivar, orientar, acompanhar e avaliar os estudantes" (BRASIL, 2007b, p. 20).

Sobre a tutoria, o texto dos referenciais de 2007 é mais detalhado. Logo no início, declara que os tutores são de fundamental importância e "[...] compóem quadro diferenciado, no interior das instituiçôes" (BRASIL, 2007b, p. 21). O que seria essa situação diferenciada o texto náo especifica, deixando ao nosso entendimento que se trata de uma situaçáo flexível e de precariedade de trabalho. Ainda no mesmo parágrafo, o texto dos referenciais expressa que o tutor "[...] deve ser compreendido como um dos sujeitos que participa ativamente da prática pedagógica" e "[...] contribuir para o desenvolvimento dos processos de ensino e de aprendizagem" (BRASIL, 2007b, p. 21). Embora se considere que tais afirmaçóes sejam amplas e apontem para várias direçóes, em relação às atividades atribuídas ao corpo docente, fica claro que, enquanto aquelas se referem ao planejamento, estas estáo muito mais direcionadas à execução. Essa questão fica mais evidente com o trecho a seguir, que atribui as atividades da tutoria a distância:

A tutoria a distância atua a partir da instituição, mediando o processo pedagógico, junto a estudantes geograficamente distantes e referenciados aos polos descentralizados de apoio presencial. Sua principal atribuição deste profissional é o esclarecimento de dúvidas através de fóruns de discussão pela internet, pelo telefone, participação em videoconferências, entre outros, de acordo com o projeto pedagógico. O tutor a distância tem também a responsabilidade de promover espaços de construção coletiva de conhecimento, selecionar material de apoio e sustentação teórica aos conteúdos e, frequentemente, faz parte de suas atribuições participar dos processos avaliativos de ensino-aprendizagem, junto com os docentes. (BRASIL, 2007b, p. 27, grifo nosso).

O trecho grifado é elucidativo, pois aborda a questão da atividade do tutor em sua real e efetiva atuação. Ainda que se faça menção às atividades de ensino, é na dimensão da aprendizagem que o tutor atua, ou melhor, no acompanhamento e no controle da aprendizagem, e isso praticamente tem-se resumido a corrigir trabalhos e provas a partir de parâmetros pré-estabelecidos, que a funçáo de tutor tem-se restringido na prática, situação esta observada no 
campo empírico, conforme expomos adiante. Assim, a questão da alienação ${ }^{8}$ inserida no processo de trabalho docente na educaçáo a distância atinge tanto o tutor como o professor, em uma evidente divisão entre os processos de ensino e os processos de aprendizagem.

Por fim, com base nos objetivos postos, apresentamos a análise de dois dispositivos que marcam a situação de precariedade na dimensão pública e a solução dada até o momento. Trata-se da Resolução/CD/FNDE no 8/2010, que "[...] estabelece orientaçóes e diretrizes para o pagamento de bolsas de estudo e de pesquisa a participantes da preparação e execução dos cursos dos programas de formação superior" (BRASIL, 2010, [s. p.]) e do Ofício Circular no 21/2011, emitido pela Diretoria de Educação a distância da CAPES (BRASIL, 2011). Demarca a Resolução/CD/FNDE no 8, de 30 de abril de 2010, em seu artigo $9^{\circ}$ :

Art. 9० A título de bolsa, o FNDE pagará mensalmente a cada beneficiário os seguintes valores:

[...] IV - Professor-pesquisador conteudista: professor ou pesquisador designado ou indicado pelas IPES vinculadas ao Sistema UAB, que atuará nas atividades de elaboração de material didático, de desenvolvimento de projetos e de pesquisa, relacionadas aos cursos e programas implantados no âmbito do Sistema, [...]. O valor da bolsa a ser concedida é de $\mathrm{R} \$ 1.300,00[\ldots]$.

$\checkmark$ - Professor-pesquisador: professor ou pesquisador designado ou indicado pelas IPES vinculadas ao Sistema UAB, que atuará nas atividades típicas de ensino, de desenvolvimento de projetos e de pesquisa, relacionadas aos cursos e programas implantados no âmbito do Sistema UAB, [...]. O valor da bolsa a ser concedida é de $\mathrm{R} \$ 1.300,00$ [...].

$\mathrm{VI}$ - Tutor: profissional selecionado pelas IPES vinculadas ao Sistema UAB para o exercício das atividades típicas de tutoria, sendo exigida formação de nível superior e experiência mínima de I (um) ano no magistério do ensino básico ou superior, ou ter formação pós-graduada, ou estar vinculado a programa de pós-graduação. O valor da bolsa a ser concedida é de $R \$ 765,00$ (setecentos e sessenta e cinco reais) mensais, enquanto exercer a função. Cabe às IPES determinar, nos processos seletivos de tutoria, as atividades a serem

80 conceito de alienação aqui empregado deriva-se da construção feita por Marx, principalmente no liuro "Manuscritos Econômico-Filosóficos", de 1844. No texto, a alienação é desenvolvida em quatro facetas, quais sejam: a alienação do homem em relação à natureza, vista como a separação entre trabalhador e o fruto do trabalho; a alienação no próprio trabalho, que diz respeito à divisão entre planejamento e execução; a alienação do homem em relação ao seu ser genérico; e, por fim, a alienação do homem em relação aos outros homens (MARX, 2004). No caso aqui desenvolvido, a principal faceta abordada é a alienação no próprio trabalho, uma vez que a divisão do trabalho evidenciada na pesquisa funda-se essencialmente na divisão entre planejamento e execução, o que culmina em uma visão cada vez mais fragmentada do todo. 
desenvolvidas para a execução dos Projetos Pedagógicos, de acordo com as especificidades das áreas e dos cursos. [...].

$\S 1^{\circ}$ Os bolsistas do Sistema UAB somente farão jus ao recebimento de uma bolsa por período, mesmo que venham a exercer mais de uma função no âmbito do Sistema UAB.

$\S 2^{\circ} \mathrm{O}$ recebimento de qualquer um dos tipos de bolsa de que trata este artigo vinculará o participante ao Sistema UAB. (BRASIL, 20I0, [s. p.]).

$\S 3^{\circ}$ Será vedado o pagamento de bolsas pelo Sistema $U A B$ ao participante que possuir vinculação a outro programa de bolsa de estudo cujo pagamento tenha por base a Lei $n^{\circ}$ I I.273/2006 e a Lei n I 1.502/2007. (BRASIL, 20 I0, [s. p.]).

Convém destacar alguns pontos do supracitado artigo da resoluçáo (BRASIL, 2010). O primeiro refere-se a duas referências ou categorias de professores, quais sejam, "professor-pesquisador conteudista" e "professor-pesquisador". De acordo com os atributos de cada um, nota-se, além da típica divisão do trabalho entre professor e tutor, que o próprio trabalho docente também é dividido entre aquele que elabora materiais e aquele que seria o responsável ou o especialista de determinada disciplina, cumprindo com atividades de planejamento e de ensino na instituição.

Outro aspecto que consideramos esclarecedor é a relação/vínculo entre professores, sejam os "pesquisadores-conteudistas" ou apenas "pesquisadores", assim como os tutores, com a instituição. Enquanto a resolução é clara ao estabelecer que o professor deve ser "[...] designado ou indicado pelas IPES vinculadas ao Sistema UAB", sem qualquer menção a processos seletivos. $\mathrm{O}$ tutor, por sua vez, deve ser "[...] selecionado pelas IPES vinculadas ao Sistema UAB" por meio de "processos seletivos". Argumentamos que é nestes dois pontos que a engenhosidade do Sistema Universidade Aberta do Brasil (UAB) demonstra a sua força operacional (BRASIL, 2010).

De acordo com a Resolução/CD/FNDE no 8/2010 (BRASIL, 2010), os professores do sistema UAB seriam os "designados ou indicados" pelas instituiçóes credenciadas. Trabalhando em troca de bolsas, não estariam impedidos pelas respectivas instituiçóes por acúmulo de outras funçóes docentes, uma vez que o recebimento da bolsa é uma atividade extra, ou seja, ela não é computada na carga horária dos professores.

Quanto à tutoria, a solução dada à situação da precariedade em vista da bolsa é expressa no Ofício Circular no 21/2011, que determina “[...] que os 
tutores do Sistema UAB tenham vínculo público” para, assim, “[...] evitar que a questáo do vínculo do tutor ao Sistema UAB seja objeto de problemas judiciais futuros" (BRASIL, 2011, [s. p.]). Essa tem sido a saída para a situação de precariedade do tutor até o momento, ou seja, a consideração da existência legal do vínculo trabalhista e a maneira de evitá-la.

Embora o Ofício Circular no 21/2011 (BRASIL, 2011) não tenha a força de um ato normativo, observa-se, ainda, que a ficha de cadastro dos bolsistas exige a comprovação do vínculo dos tutores com o setor público, ou seja, sem vínculo o sistema de gerenciamento das bolsas não permite o cadastro. Isso demonstra ainda mais a intenção da Capes em resolver de forma sub-reptícia a questão, pois tal exigência, transformada em ato normativo do poder público, poderia ser amplamente questionada.

\section{Organização do trabalho docente e precariedade: aspectos concretos}

Evidenciamos agora algumas constataçóes e desdobramentos verificados no campo empírico, constituído pelas IES aqui denominadas Universidade Federal Alfa e Universidade Privada Beta.

De acordo com algumas informaçóes obtidas na Universidade Federal Alfa, visualizadas na Tabela 1, percebem-se as seguintes situaçóes: a relação entre o número de matrículas pelo total de professores é de 12,9; a relação entre o número de matrículas pelo total de tutores é de 16,5; do total de professores, ou seja, dos 87 professores que atuam na Instituição, 59 deles $(67,8 \%)$ encontram-se em situação de intensificação do trabalho - uma vez que são professores efetivos que aceitam trabalhar mais em troca de uma bolsa - ou em situação de precariedade - pois não são efetivos, e apenas a bolsa não garante os mesmos direitos trabalhistas referentes a férias, $13^{\circ}$ salário etc. 
Tabela I - Número de Matrículas, polos, tutores a distância, tutores presenciais, professores efetivos, professores efetivos com bolsa e Professores não efetivos com bolsa, nos cursos de graduação, modalidade a distância, na Universidade Federal Alfa (20l4).

\begin{tabular}{lccccccc}
\hline \multicolumn{1}{c}{ Curso } & Matrícula & Polo & $\begin{array}{c}\text { Tutor a } \\
\text { distância }\end{array}$ & $\begin{array}{c}\text { Tutor } \\
\text { presencial }\end{array}$ & $\begin{array}{c}\text { Professor } \\
\text { efetivo }\end{array}$ & $\begin{array}{c}\text { Professor } \\
\text { efetivo } \\
\text { com } \\
\text { bolsa }\end{array}$ & $\begin{array}{c}\text { Professor } \\
\text { não } \\
\text { efetivo } \\
\text { com bolsa }\end{array}$ \\
\hline $\begin{array}{l}\text { Adm. } \\
\text { Pública }\end{array}$ & 234 & 4 & 8 & 5 & 3 & 10 & 3 \\
$\begin{array}{l}\text { Ciências } \\
\text { Biológicas }\end{array}$ & 289 & 7 & 0 & 7 & 5 & 13 & 11 \\
$\begin{array}{l}\text { Geografia } \\
\text { Letras }\end{array}$ & 70 & 3 & 0 & 3 & 2 & 1 & 2 \\
Matemática & 161 & 7 & 13 & 7 & 5 & 0 & 5 \\
Pedagogia & 190 & 6 & 6 & 6 & 6 & 1 & 6 \\
Total & 1124 & 32 & 35 & 33 & 28 & 25 & 34 \\
\hline
\end{tabular}

Fonte: Elaboração dos autores com base nas informações obtidas por meio de Entrevistas e na Secretaria de Controle Acadêmico da Instituição Alfa.

Quanto à tutoria, além da situação contratual precária, é fundamental ressaltar que nenhum dos cursos disponibiliza espaço ou condiçóes de trabalho, sobrando para os tutores a responsabilidade de trabalhar com equipamentos próprios e em local de trabalho improvisado.

Outro fato que chama a atenção na Universidade Federal Alfa é que, embora em dois cursos os professores auxiliem os tutores na correção das atividades, esta aparece como a principal atividade dos tutores. Como eles não participam do planejamento das atividades, evidencia-se a clássica divisão taylorista entre planejamento e execução, o que, em última análise, pode ser considerado como um processo alienado de trabalho.

Sobre a Universidade Privada Beta, que integra a camada das cinco instituiçóes com o maior número de matrículas, antes da exposição-síntese das constataçôes, é preciso ponderar sobre o caminho metodológico. Uma vez que não obtivemos sucesso na colaboraçáo da instituição no fornecimento dos dados, as informaçóes que apresentamos são resultados de inferência estatística, composta pela amostra de 110 tutores de uma populaçáo de 400 - o 
que garantiu um grau de confiança de 95\% (LEVIN; FOX, 2004) - e de entrevistas semiestruturadas com professores e tutores. Em face ao exposto, com referência à relação educacional entre professor e aluno na IES, o relato a seguir, feito por um professor, que declarou não saber o número total de alunos e ministrar aulas para mais de 50 polos, demonstra a mediação e a separação total entre professor e aluno. Ao esclarecer se o professor respondia aos e-mails dos alunos, o entrevistado assim se manifestou:

Não. A interação do aluno com o professor é via Moodle, via tutor a distância. As dúvidas não vão para o professor. Eles não entram em contato direto com o professor, não existe o e-mail do professor no Moodle. É o tutor a distância via Moodle (Entrevistado - Universidade Beta, 2014, [s.p] ).

Ao se considerar que o contato se configura como mínimo entre professor e aluno, uma indagação decorrente seria se o contato entre o professor e tutor seria frequente, pois, assim, talvez o professor, ainda que atuando como mediador, teria maior conhecimento sobre a efetivação do seu trabalho. De acordo com o tutor entrevistado:

Não, não tem quase contato nenhum com os professores da disciplina. Eles não repassam nada para a gente. A única coisa que eles passam são os gabaritos das provas e dos desafios de aprendizagem. Eu estou lá desde novembro de 2010 e teve uma exceção, uma professora que fez uma reunião com todos os tutores a distância e explicou o conteúdo da disciplina e como deveriam ser feitas as atividades e correções. Mas isso foi somente um caso, uma exceção (Entrevistado - Universidade Beta, 20l4, [s.p]).

O relato a seguir demonstra a total separaçáo entre o trabalho do professor e a sua objetivação; logo, sua alienação do resultado do processo de trabalho, além da situaçáo de trabalho intenso dos tutores.

Entrevistador: Sobre o processo de trabalho docente, quais são as principais atividades de ensino que desenvolve e quais as atividades que mais ocupam o seu tempo de trabalho? Entrevistado: No caso, o professor tutor a distância, [...], os únicos dois trabalhos que eles têm é corrigir as provas dos alunos, de todas as disciplinas, e mais os desafios de aprendizagem, [...]. É um trabalho longo, onde temos que ver se não há plágio ou cópia de outros grupos, depois lançamos as notas no sistema. Essas são as duas principais atividades que fazemos: corrigir provas e desafios. [...]. Não há feedback dizendo onde ele errou, onde devia melhorar, ou mostrados os sites de onde copiou, isto não acontece (Entrevistado Universidade Beta, 2014, [s.p]). 
Por fim, outro fator que expressa as particularidades da essência da organização do trabalho docente a distância e sua efetiva produtividade, que integra tanto aspectos relativos à divisão quanto à intensificaçáo do trabalho, diz respeito à relação entre tutor e aluno. De acordo com o Gráfico 6, mediante as respostas dos 110 tutores da Universidade Privada Beta, obtém-se a média de 199 alunos por tutor. Conforme a Tabela 1, tal relação, na Universidade Federal Alfa foi, em média, 16,5.

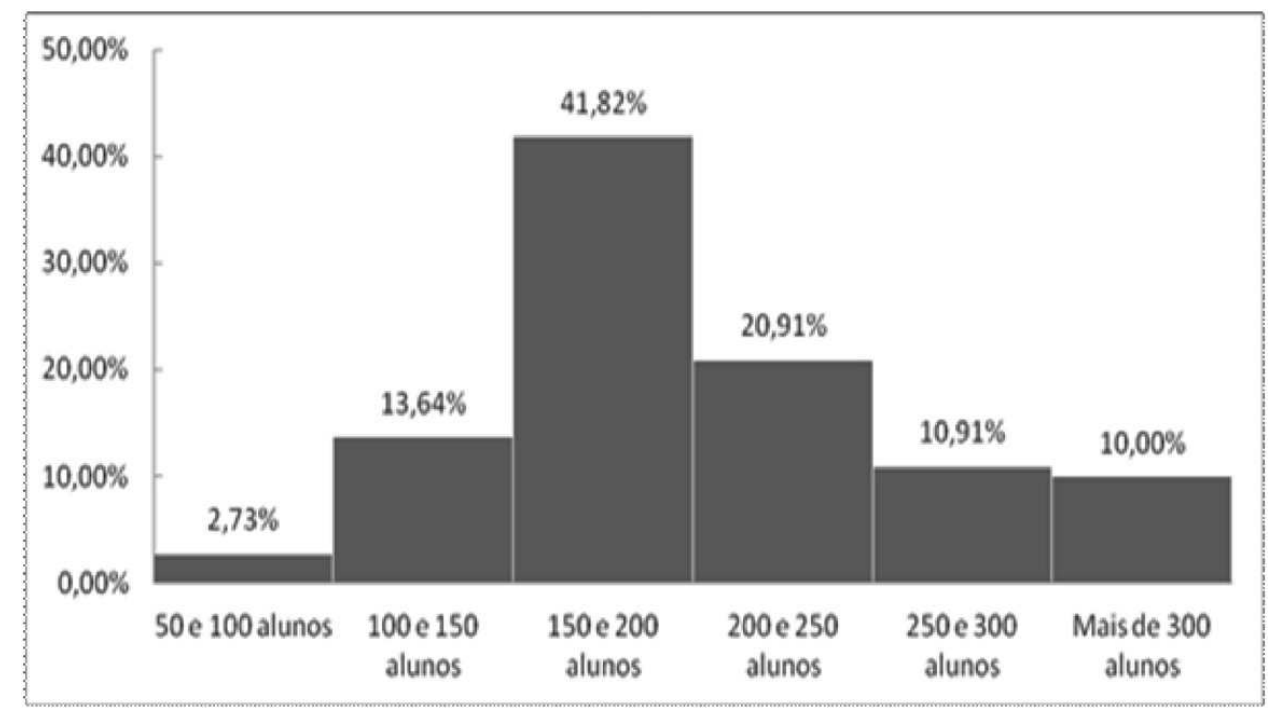

\section{Gráfico 6 - Relação de alunos por tutores a distância na Universidade Privada Beta}

Fonte: Elaborado pelos autores, a partir dos dados obtidos na Instituição Privada Beta.

\section{Considerações finais}

$\mathrm{O}$ avanço da educação a distância, expresso no concreto imediato e singular das matrículas do ensino superior, constituído pelas relações entre o político e o econômico, o público e o privado, modalidade presencial e a distância, demonstra a sua essência na organizaçáo racional e instrumental, precária, intensa, e alienante do trabalho docente.

De fato, a concretude de tal modalidade, inserida nas determinaçóes dos aspectos universais da organização capitalista do trabalho, ao viabilizar maior produtividade, ainda que existam particularidades importantes nas dimensóes pública e privada, conforme analisadas, apontou para aspectos funcionais 
claros para as duas dimensões, quais sejam: o incremento de matrículas e o decorrente processo de democratização do acesso ao ensino superior na dimensão pública essencialmente construída pela intensificação, alienação e precarização do trabalho, sendo o procedimento bolsa um dos principais elementos; e a ampliação da esfera de acumulação do capital, na dimensão privada do ensino superior, cuja contradição encontra-se na alienação total da relação educativa entre professor e aluno, e sua intensificaçáo do trabalho.

Sobre essa precarização da educação a distância, ainda que aqui existam contratos e todas as garantias legais, é importante considerar que a situação de incerteza reside na própria lucratividade e sua expansão ou, ainda, na sustentabilidade e manutenção da acumulação ampliada do capital, uma vez que o setor privado é formado, de forma hegemônica, por capital aberto e financeiro.

\section{Referências}

BELLONI, M. L. Educação a distância. 5. ed. Campinas: Autores Associados, 2009.

BENINI, E. G. Política educacional e educaçáo a distância: as contradições engendradas no âmbito do trabalho docente. 2012. Tese (Doutorado em Educação) Programa de Pós-Graduação em Educação - Universidade Federal de Mato Grosso do Sul, Campo Grande, 2012.

BRASIL. Câmara dos Deputados. Comissão de Educação, Cultura e Desporto. Coordenaçãa de Publicações. LDB \& Lei do Fundef. Brasília, DF: Câmara dos Deputados, 2001a.

. Decreto no 2.494, de 10 de fevereiro de 1998. Regulamenta o art. 80 da Lei no 9.394, de 20 de dezembro de 1996, e dá outras providências. Diário Oficial da Uniáo, Brasília, DF, 11 fev. 1998a. Disponível em: <http://www.planalto.gov.br/ccivil_03/decreto/D2494.htm>. Acesso em: 10 maio 2011.

. Decreto no 2.561, de 27 de abril de 1998. Altera a redaçáo dos arts. 11 e 12 do Decreto no 2.494, de 10 de fevereiro de 1998, que regulamenta o disposto no art. 80 da Lei no 9.394, de 20 de dezembro de 1996. Diário Oficial da Uniáo, Brasília, DF, 28 abr. 1998b. Disponível em: <http:// www.planalto.gov.br/ccivil_03/decreto/D2561.htm>. Acesso em: 10 maio 2011.

Decreto no 5.622, de 19 de dezembro de 2005. Regulamenta o art. 80 da Lei no 9.394, de 20 de dezembro de 1996, que estabelece as diretrizes e bases da educação nacional. Diário Oficial da União, Brasília, DF, 20 dez. 2005. Disponível em: <http://www.planalto.gov.br/ccivil_03/_ ato2004-2006/2005/Decreto/D5622.htm>. Acesso em: 10 maio 2011. 
. Decreto n 5.773, de 9 de maio de 2006. Dispóe sobre o exercício das funçôes de regulação, supervisão e avaliação de instituições de educação superior e cursos superiores de graduação e sequenciais no sistema federal de ensino. Diário Oficial da Uniáo, Brasília, DF, 10 maio 2006. Disponível em: <http://www.planalto.gov.br/ccivil_03/_ato2004-2006/2006/Decreto/D5773. htm>. Acesso em: 10 maio 2011.

. Decreto $\mathrm{n}^{\circ}$ 6.303, de 12 de dezembro de 2007. Altera dispositivos dos Decretos ${ }^{\text {os }} 5.622$, de 19 de dezembro de 2005, que estabelece as diretrizes e bases da educação nacional, e 5.773, de 9 de maio de 2006, que dispóe sobre o exercício das funções de regulação, supervisão e avaliação de instituiçôes de educação superior e cursos superiores de graduação e sequenciais no sistema federal de ensino. Diário Oficial da Uniáo, Brasília, DF, 13 dez. 2007a. Disponível em: <http://www. planalto.gov.br/ccivil_03/_Ato2007-2010/2007/Decreto/D6303.htm>. Acesso em: 10 maio 2011.

Lei no 9.394, de 20 de dezembro de 1996. Estabelece as diretrizes e bases da educação nacional. Diário Oficial da Uniáo, Brasília, DF, 23 dez. 1996b. Disponível em: <http://www. planalto.gov.br/ccivil_03/leis/19394.htm>. Acesso em: 15 de ago. 2011.

. Lei no 10.172, de 9 de janeiro de 2001. Aprova o Plano Nacional de Educaçáo e dá outras providências. Diário Oficial da Uniáo, Brasília, DF, 10 jan. 2001b. Disponível em: <http://www. planalto.gov.br/ccivil_03/leis/leis_2001/110172.htm>. Acesso em: 10 maio 2011.

Ministério da Educação. Fundo Nacional de desenvolvimento da Educação. Resolução/ CD/FNDE no 8, de 30 de abril de 2010. Altera os incisos I a V do art. $9^{\circ}$, o $\$ 1^{\circ}$ do art. 10 e o item 2.4 do Anexo I da Resolução CD/FNDE no 26/2009, que estabelece orientaçóes e diretrizes para o pagamento de bolsas de estudo e de pesquisa a participantes da preparaçáo e execuçáo dos cursos dos programas de formaçáo superior, inicial e continuada no âmbito do Sistema Universidade Aberta do Brasil (UAB). Diário Oficial da Uniáo, Brasília, DF, 10 jan. 2001. Disponível em: $<$ https://www.fnde.gov.br/fndelegis/action/UrlPublicasAction.php?acao=abrirAtoPublico\&sgl_ tipo=RES\&num_ato=00000008\&seq_ato=000\&vlr_ano=2010\&sgl_orgao=CD/FNDE $/ \mathrm{MEC}>$. Acesso em: 20 jul. 2011

Ministério da Educaçãa. Fundo Nacional de desenvolvimento da Educaçãa. Coordenaçáo de Aperfeiçoamento de Pessoal de Nível Superior. Diretoria de Educação a distância. Ofício Circular no 21/2011- DED/CAPES. Brasília, 16 de dezembro de 2011. Disponível em: <http:// www.ufrgs.br/sead/sead-2/legislacao-ead/documentos/Oficio_Circular_21_-_2011dedcapes.pdf/ view>. Acesso em: 15 jan. 2014.

Ministério da Educação. Portaria no 2.253, de 18 de outubro de 2001. Dispóe sobre a introdução nas instituições de ensino superior do sistema federal de ensino, na organização pedagógica e curricular de seus cursos superiores reconhecidos, a oferta de disciplinas que, em seu todo ou em parte, utilizem método não presencial, com base no art. 81 da Lei no 9394, de 1996. 
Diário Oficial da Uniáo, Brasília, DF, 19 out. 2001c. Disponível em: <http://www2.camara.leg. br/legin/marg/portar/2001/portaria-2253-18-outubro-2001-412758-norma-me.html>. Acesso em: 15 de ago. 2011.

. Ministério da Educação. Secretaria de educação a distância. Indicadores de qualidade em cursos de graduaçáo a distância. Brasília, 2000. Disponível em: <http://www.ead.unifei.edu.br/ Legislacao/files/05-indicadores-de-qualidade.pdf>. Acesso em: 15 de ago. 2011.

Ministério da Educação. Secretaria de educação a distância. Referenciais de qualidade para a educaçáo a distância. Brasília, 2003. Disponível em: <http://www2.ufscar.br/ead/ documentos/referenciaisdeEAD.pdf>. Acesso em: 15 de ago. 2011.

Ministério da Educação. Secretaria de Educação a distância. Referenciais de qualidade para a educação superior a distância - versão preliminar. Brasília, jun. 2007b. Disponível em: $<$ http://portal.mec.gov.br/seed/arquivos/pdf/referenciaisead.pdf>. Acesso em: 20 jan. 2010.

DANIEL, J. Mega-Universities and knowledge Media: Technology Strategies for Higher Education. London: Kogan Page, 1999.

DELORS, J. et al. Educaçáo: um tesouro a descobrir. Relatório para a UNESCO da Comissão Internacional sobre Educação para o século XXI. São Paulo: Cortez, 1996.

GIOLO, J. A educação a distância e a formação de professores. Educação e Sociedade, v. 29, n. 105, p. 1211-1234, set./dez. 2008. Disponível em: <http://www.scielo.br/pdf/es/v29n105/ v29n105a13.pdf>. Acesso em: 10 de maio 2011.

INSTITUTO NACIONAL DE ESTUDOS E PESQUISAS EDUCACIONAIS ANÍSIO TEIXEIRA. Sinopses da educação superior: 2000-2012. 2012. Disponível em: <http://portal. inep.gov.br/superior-censosuperior-sinopse>. Acesso em: 10 jan. 2014.

LANCILLOTTI, S. S. P. A constituiçáo histórica do processo de trabalho docente. 2008. Tese (Doutorado em Educação) Programa de Pós-Graduação em Educação - Universidade Estadual de Campinas, Campinas, 2008.

LEVIN, J.; FOX, J. A. Estatística para ciências humanas. 9. ed. São Paulo: Pearson Prentice Hall, 2004.

LITTO, F. M.; FORMIGA, M. (Org.). Educação a Distância: o estado da arte. São Paulo: Pearson Education do Brasil, 2009.

MARX, K. Contribuição à Crítica da Economia Política. 3. ed. Tradução de Maria Helena Barreiro Alves. São Paulo: Martins Fontes, 2003.

Manuscritos Econômico-Filosóficos. Tradução, apresentação e notas de Jesus Ranieri. São Paulo: Boitempo Editorial, 2004. 
MÉSZÁROS, I. Para além do capital: rumo a uma teoria da transição. Tradução de Paulo Cezar Castanheira e Sérgio Lessa. São Paulo: Boitempo Editorial, 2002.

MILL, D. Estudos sobre processos de trabalho em educaçáo a distância mediada por tecnologias da informação e da comunicação. 2002. Dissertação (Mestrado em Educação) Programa de PósGraduação em Educação- Universidade Federal de Minas Gerais, Belo Horizonte, 2002.

MOORE, M. G.; KEARSLEY, G. Educação a distância: uma visão integrada. Tradução de Roberto Galman. São Paulo: Thomson Learning, 2007.

NEDER, M. L. C. A formação do professor a distância: desafios e inovaçóes na direção de uma prática transformadora. Cuiabá: EdUFMT, 2009.

NOBLE, D. De volta à ruína? Ensino a distância, lucros e mediocridade. Le monde diplomatique Brasil. 1 abr. 2000, [s. p.]. Disponível em: <http://www.diplomatique.org.br/acervo.php?id=209>. Acesso em: 7 maio. 2011.

Digital Diploma Mills: The Automation of Higher Education. New York: Monthly Review Press, 2002.

PETERS, O. A educaçáo a distância em transição: tendências e desafios. Tradução de Leila Ferreira de Souza Mendes. São Leopoldo: Ed. Unisinos, 2009.

Didática do ensino a distância: experiências e estágio da discussão numa visão internacional. Tradução de Ilson Kayser. São Leopoldo: Ed. Unisinos, 2006.

Recebido em: 21.04.2014

Aprovado em: 29.10.2014

\section{Distance education: feasures, policies and contradictions engendered in the teacher's work}

\section{Abstract}

The paper aims to unveil the contradictions that arise in the teachers' work organization within the context of distance education. The analytical framework included the systematization of the educational data provided by the "Anísio Teixeira National Institute for Educational Studies and Research (Inep)", the study of the documents that guide the national educational policy and empirical research carried out in higher education institutions. The results support that the Information and Communication Technologies (ICT) constitute the objective base upon which 
Educação a distância: configurações, políticas e contradições engendradas no trabalho docente | Elcio Gustavo Benini, Maria Dilnéia Espíndola Fernandes e Carla B. Zandavalli M. Araujo

speeches and practices for the democratization of access to higher education rely. The first decade of this century witnessed an enormous growth in distance education enrollment at universities. The increase, however, has triggered some contradictions such as alienation, precariousness, and the division of the teachers' work.

Keywords: Educational Policy. Distance Education. Teachers' work. 